\title{
Screening of Endophytes from Traditionally Used Medicinal Plants of Manipur for Their Antimicrobial Activity: An Impact towards Future Drug Discovery
}

\author{
Ng Ngashangva ${ }^{1}$, Indira Devi $\mathrm{S}^{2}$, Kalita M. C. ${ }^{3}$ \\ ${ }^{1,2}$ Institute of Bioresources and Sustainable Development (IBSD), A National institute of Department of Biotechnology, \\ Government of India, Takyelpat, Imphal-795001, Manipur, India \\ ${ }^{3}$ Department of Biotechnology, Gauhati University, Guwahati-781014, Assam, India
}

*Corresponding author address: indiraibsd@gmail.com

Available online at: www.isroset.org

Received: 28/Sept/2019, Accepted: 15/Oct/2019, Online: 31/Oct/2019

\begin{abstract}
Antimicrobial resistance has been developing fast and continuing to challenge the world medical sector. New strategies are needed to address this challenge that is incurring huge loss on human life. Medicinal plants from the untapped rainforest of the North-East India has a huge potential to find microbes that produce novel biomolecules. Bioactive endophytes were isolated from traditionally used medicinal plants. Paenibacillus spp. from Millettia spp. in a fermentation broth has shown strong and broad-spectrum of activity at the range of $1600 \mathrm{AU} / \mathrm{ml}$. Unexplored region has huge prospect to find novel biomolecules which can be harvested in scientific, economical and environmentally friendly. Moreover, it has shown that the traditional medicinal plant harboured bioactive. Moreover, it will provide insights into its metabolic potential and ecological role of this species.
\end{abstract}

Keywords: Endophyte, antimicrobial, supernatant, resistance, medicinal plants

\section{INTRODUCTION}

The introduction of penicillin has heralded the modern era of drug which had saved millions of lives. However, the resistance has been developing fast and continuing to challenge the world medical sector, and new strategies are needed to address this challenge which incurred huge loss on human life [1]. The major causes of antimicrobial resistance (AMR) is attributed to over-prescription, incomplete treatment regime, overuse, poor infection control and poor hygiene [2,3]. To worsen the matter, addition of new antimicrobial agent is diminishing because of rapid resistant development, prolonged research and lack of profit from antibiotics research [4]. Therefore, a new lead compound is required to address this formidable challenge $[5,6]$.

Bioprospecting the unexploited environment with strong selecting factor is essential to enrich novel secondary metabolites (SMs) for our agriculture, medicine and industrial development [7]. There is a huge potential from the untapped rainforest of the North-East India herein the flora and fauna diversity are very rich [8] and especially, traditionally used medicinal plants which might be harbouring a number of valuable microbes including endophytes [9]. One of the methods used to narrow the search is to utilize the knowledge of native people who have relied on plants as medicines for centuries. It may be possible that the bioactive compounds within the plant may not be the solitary product of the plant, but products of the microbes that exist in association with the host plant [10]. The selected medicinal plants are Sapindus trifoliatus, Millettia pachycarpa, Oroxylum indicum, and an unidentified vine plant which is used in traditional fermentation [11, 12]. S. trifoliatus has been used for the treatment of ulcers, external wounds, inflammation, epilepsy, dental caries, arthritis, joint pain, gout and rheumatism. The crude extracts possess antimicrobial, anticancer, spermicidal, hepatoprotective, antioxidant, antiinflammatory, anti-platelet aggregation, anti-hyperlipidemic, anti-migraine, anti-diabetic, anti-ulcerogenic and analgesic properties [11]. O. indicum has been used for the prevention and treatment of jaundice, arthritic and rheumatic problems, gastric ulcers, tumors, respiratory diseases, diabetes, and diarrhea and dysentery [12]. Millettia pachycarpa is traditionally used for nerve pain, migraine, insomnia, anxiety, fear and nervous tension [13]. It is used as crab repellents in paddy fields, treatment for animal infection and as fish poison in traditional fishing [14].

\section{MATERIAL \& METHODS}

\section{Reagents and media}

The media were from Hi Media, (Mumbai, India). All solvents (HPLC grade) were from Rankem (Haryana, India). 
All molecular reagents were from Sigma (Darmstadt, Germany). All the instruments and media were wrapped with aluminium seal and hand crimped tightly to prevent air leakage and autoclaved (Panasonic MLS-3751L).

\section{Sample collection}

Medicinal plants were collected from different location and time in Ukhrul, Manipur consulting with the traditional healers as per their common usage method, part uses and traditional knowledge (Table 1) [8, 10]. The harvesting method was performed with cautions that may cause minimum damage to the plants.

Table 1: The selected medicinal plants from different locations, method of uses and their parts uses.

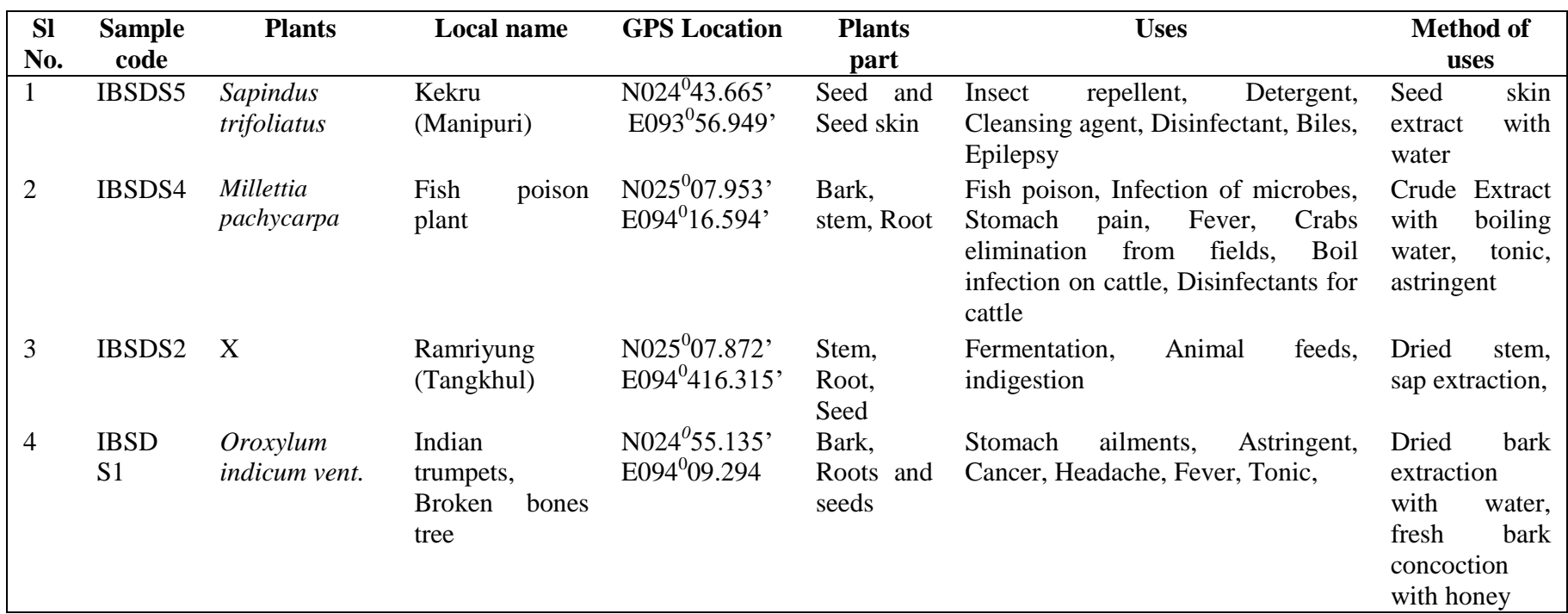

Surface sterilization method for endophyte strain isolation

The plant stems were thoroughly rinsed on running tap water and washed with Tween 20 (Hi Media, Mumbai, India) to wash off the soil debris [15]. Subsequently, the samples (2 inches) were sequentially treated with the chemicals (Table 2). They were then successively dissected into pieces using forceps and sharp blades and dried in Laminar Air hood for $10 \min [16]$.

\section{Isolation of endophytes from traditionally used medicinal plant}

The cut sample pieces were inoculated on (Luria bertani) LB agar plates to isolate the bacterial endophyte and the replicas on (Potato Dextrose agar) PDA plates for fungi. The inoculated plates were incubated at $25^{\circ} \mathrm{C}$ concurrent with the climatic condition of the plant's habitats [17]. The controlled aseptic sterilization was performed by spreading residue of the final washing distilled water $(200 \mu \mathrm{l})$ on LB agar and PDA plates and incubated as mentioned above [18].

\section{In vitro antimicrobial susceptibility test of the isolates}

The in vitro antimicrobial susceptibility test was performed by Spot-on-lawn antimicrobial bioassay. The isolate colonies were spotted on Muller Hilton Agar (MHA) lawn (w/v 1\% agar) seeded with test strains [19]. The inoculants were incubated at $37^{\circ} \mathrm{C}$ overnight $(\mathrm{ON})$ as per the test pathogens favourable condition (Table S1).
The bioactive endophyte was selected and the activity spectrum was determined from the representative test pathogens viz. Escherichia coli ATCC 13525, Bacillus subtillus ATCC 6633, Staphylococcus aureus ATCC 25923, Pseudomonas fluorescens ATCC 13525, Klebsiella pneumonia ATCC4352. The colony that shown potent and broad spectrum of antimicrobial activity (AA) was selected for further study to isolate the antimicrobial metabolites.

\section{Selection of the endophytes for further study}

The colony that showed halo zone of inhibition were measured (Antimicrobial susceptibility Scale, Hi Media) and photographed (Figure 3a, b, c, d). The isolates that had shown strong and broad spectrum of antimicrobial activity on preliminary screening were selected for more specific study from its fermentation in Brain Heart Infusion (BHI) Broth (Figure 3). It's antimicrobial secondary metabolites (SMs) production was tested from its crude extract (colonies that did not show AA were not selected neither shown).

Morphological, phenotypic and genotypic characterization of the most potent bioactive endophyte The morphological characteristics of the selected bioactive endophyte that shown strong and broad spectrum of activity were examined using the keys of Bergey's manual of determinative bacteriology [20]. The phenotypic characters were determined with Gram-staining [21]. The motility was tested by hanging drop method and observed on concave 
glass slide with Phase contrast microscope (Zeiss, Imager. Z2) [20]. The crude extract arbitrary unit of activity was calculated.

\section{Time-kill Analysis}

The time-kill study was performed with the selected test pathogen to further define the antibacterial activity of the crude extract [22]. Moreover, it allows to assess the rate of bactericidal activity at varying antimicrobial agent concentrations over time. The time-killing curve study was performed in duplicate using concentrations or dose of 0.5 , $1,1.5,2,2.5,3,3.5$, and $4 \mathrm{X}$ MIC of crude extract for $24 \mathrm{hr}$ of incubation. The activity was observed at every $\mathrm{hr}$ and plated on the MHA agar to count the colony.

The test strains, S. aureus ATCC 25923 was grown as described before [23]. To minimize the effect of antibiotic carryover, the samples were centrifuged (15000 rpm, $5 \mathrm{~min}$, $4^{\circ} \mathrm{C}$ ) before plating out and the antibiotic medium was replaced with fresh BHI broth. The positive control is without antimicrobial agent and the negative control is without test microorganisms but with antimicrobial agents.

\section{The effect of manganese and Tween80 on antimicrobial bioactive molecule production}

Among the variables in media (proteins, $\mathrm{pH}$, phosphate, osmolality, salt concentrations and divalent cations) divalent cations are known to affect the bactericidal activity of certain antimicrobial agents and microorganisms [24]. At regular intervals of incubation time, each of $4 \mathrm{ml}$ broth samples from separate fermentation broth of BHI alone and manganese and Tween 20 supplemented broth were aspirated out aseptically and their OD at $\lambda 600$ and $\mathrm{pH}$ were measured (Figure 2).

\section{LC/MS analysis of the dialysate}

The fermentation broth inoculated with IBSD35 strain were centrifuged. The supernatant was dialysis with 12400 kilodalton ( $\mathrm{kDa}$ ) Molecular weight cut off (MWCO) dialysis tube and analysed with Liquid chromatography-mass spectrometry (LC/MS) to find the total antimicrobial biomolecules in the genome. The antimicrobial peptide backbone sequences were enzymatically digested with trypsin and ionized using low energy Collision-induced dissociation (CID), Computer-Aided Design (CAD), and Infrared multiple photon dissociation (IRMPD) ( $\mathrm{y}$ and $\mathrm{b}$ proteinated peptide ions). PEAKS 6.0 software de novo sequencing was carried out in order to obtain sequences or partial sequences of protein/peptide sequences from the MS/MS data $[25,26]$.

\section{RESULTS}

\section{Collection of medicinal plant}

Traditionally used medicinal plants viz. S. trifoliatus, Millettia pachycarpa, $O$. indicum and an unidentified vine were collected in consultation with the traditional medicine practitioners (Figure 1). It was selected with the idea that the medicinal plants might be harbouring numbers of valuable endophytes $[27,7,9]$.

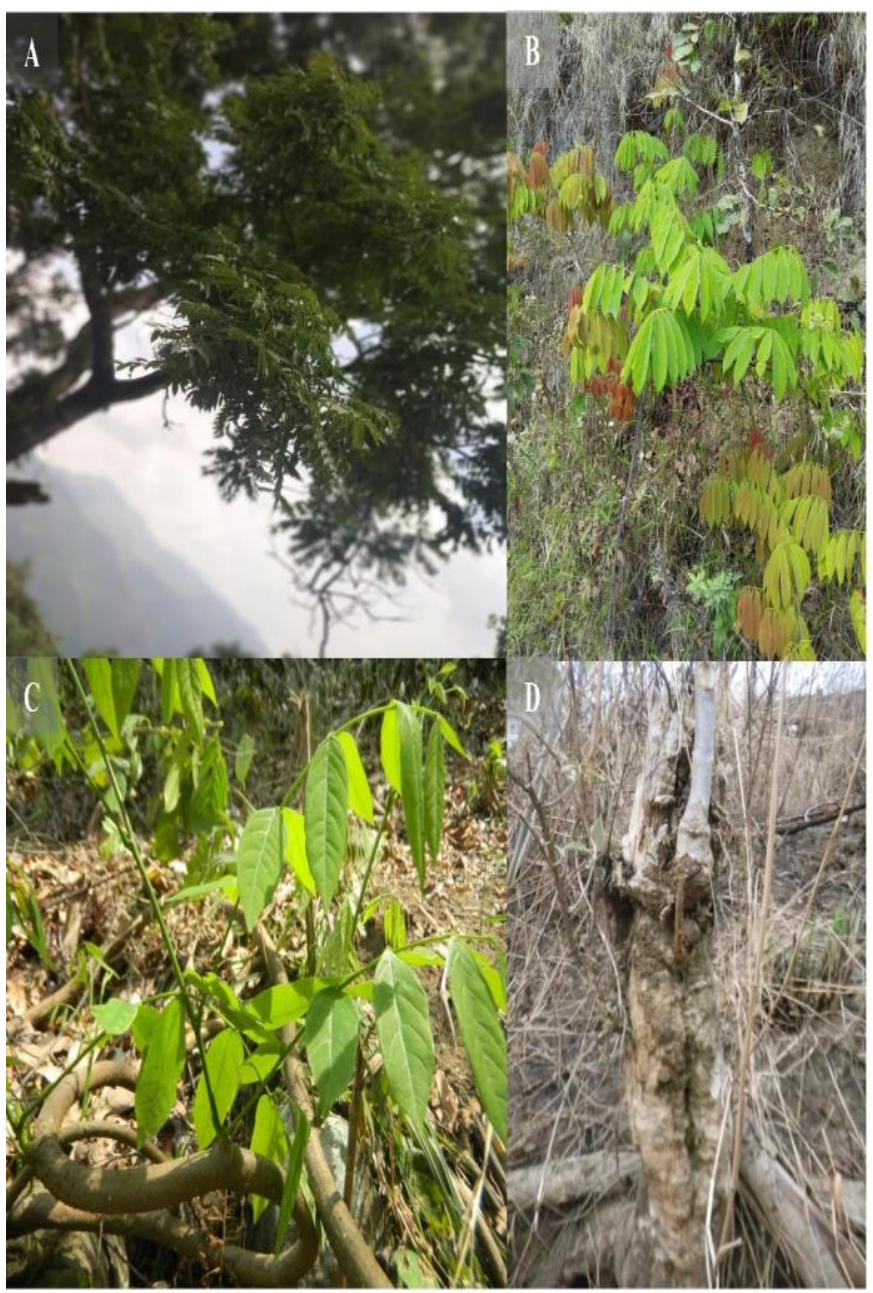

Figure 1: Traditionally used medicinal plants selected in consultation with the traditional medicine practitioners (a) $S$. trifoliatus (b) Millettia spp. (c) Unknown (d) O. indicum.

\section{Surface sterilization of the plant sample}

The plant stems were wash, rinsed and cut into pieces. The samples (2 inches) were sequentially treated with the chemicals as shown in table 2 . The samples were dried in Laminar Air hood for $10 \mathrm{~min}[15,16]$. The samples were inoculated on the LB agar plates to support the bacterial endophytes growth and the replicas on PDA plates for fungal growth. The inoculants were incubated and observed for a week. The final washing $(200 \mu \mathrm{l})$ spread on LB and PDA plates showed non-contamination and effective sterilization [18]. 
Table 2: Standardized surface sterilization with sequential treatment of $75 \%$ ethanol for 5 min, $0.5 \%$ Mercuric Chloride $\left(\mathrm{HgCl}_{2}\right)$ for $3 \mathrm{~min}, 3.125 \%$ Sodium hypochlorite $(\mathrm{NaOCl})$ for $3 \mathrm{~min}$, and $75 \%$ ethanol for 3 min, followed by 5 times washing with sterile distilled $\mathrm{H}_{2} \mathrm{O}$ for 1 min each aseptically.

\begin{tabular}{|ccc|}
\hline Chemical & Percentage & Duration (min) \\
\hline Dist. $\mathrm{H}_{2} \mathrm{O}$ & 100 & $3 \mathrm{X}$ \\
Ethanol & 75 & 5 \\
$\mathrm{HgCl}_{2}$ & 0.5 & 3 \\
$\mathrm{NaOCl}$ & 3.125 & 3 \\
Ethanol & 75 & 3 \\
Dist. $\mathrm{H}_{2} \mathrm{O}$ & 100 & $5 \mathrm{X}$ \\
\hline
\end{tabular}

Isolation of endophytes from the elected medicinal plants

The endophytes were isolated from the plants stem with sequential treatment of chemicals (Table 2). At least five were isolated from Millettia pachycarpa, two from S. trifolatus, three from $O$. indicum and three from an unidentified vine. Total thirteen endophytes were isolated from the selected four medicinal plants (Table S2). When colonies were clearly visible on the third day of incubation. The colonies were then picked and sub-cultured repeatedly on BHI agar until pure colonies were established. The pure colonies were preserved at $4^{\circ} \mathrm{C}$ and finally in $20 \%$ glycerol at $-80^{\circ} \mathrm{C}$ in LB broth (New Brunswick Ultra Low Freezer U725 Innova) until further use.

\section{Antimicrobial activity of the microbial endophytes}

The preliminary in vitro antimicrobial susceptibility test was performed using Spot-on-lawn antimicrobial bioassay in which a single pure colony or isolate was spotted on Muller Hilton Agar (MHA) $(20 \mathrm{ml}, \mathrm{w} / \mathrm{v} 1 \%$ agar) seeded with test strains $(50 \mu \mathrm{l})$ of 0.5 Macfarland standard $\left(1.5 \times 10^{8} \mathrm{CFU} / \mathrm{ml}\right)$ lawn. The nine endophytes had shown different antimicrobial activity from the selected test pathogens. The clear inhibition zones were measured (Table 3).

Table 3: Antimicrobial activity of the endophytes against different pathogens from different plants and their parts. (Numerical value with plus indicated the positive and the zone of inhibition diameter in $\mathrm{mm}$, and the small dash indicated non activity).

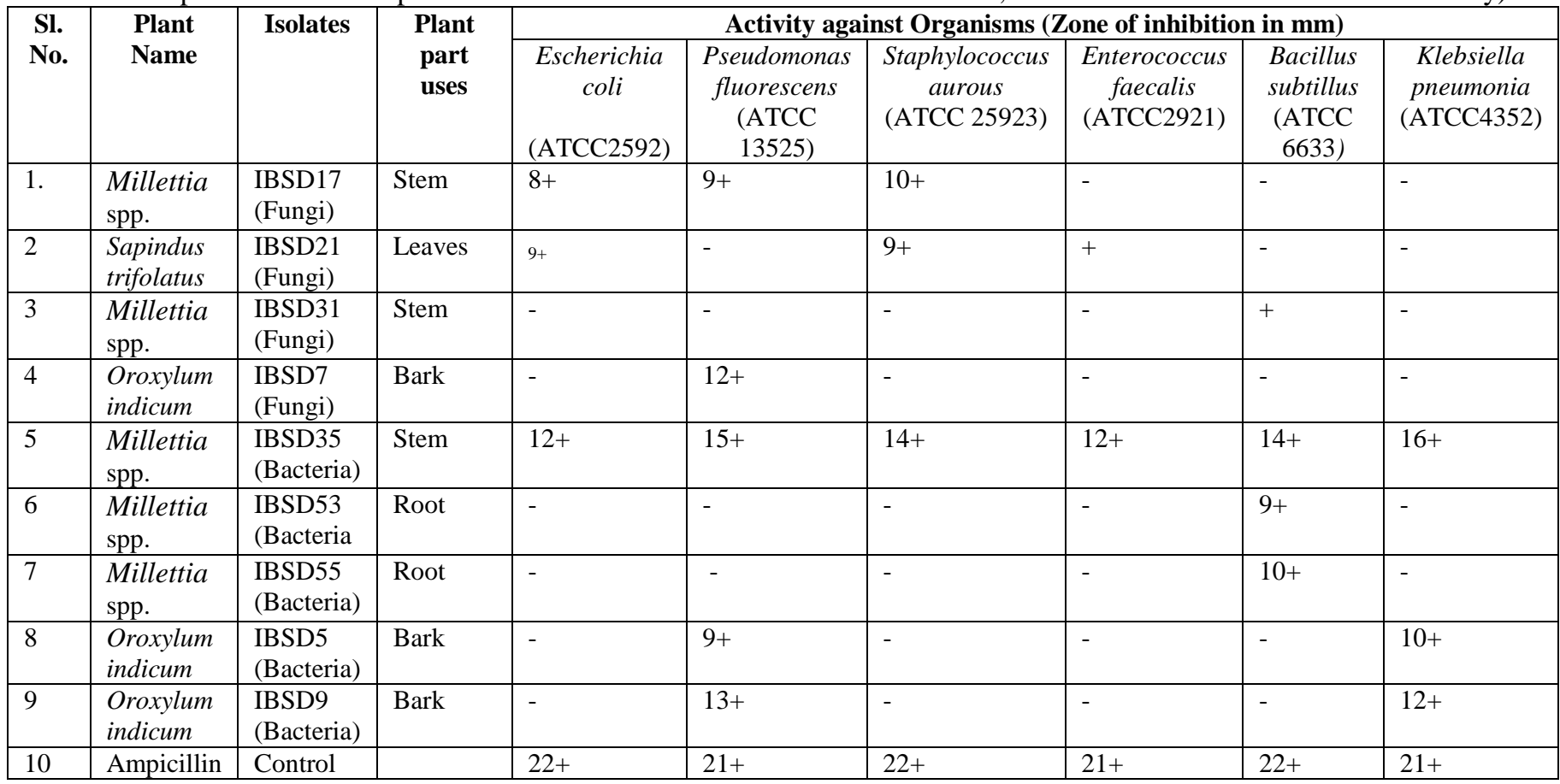

Amongst the positive action of antimicrobial susceptibility on test organisms, strain IBSD35 which has shown broad spectrum activity was selected for further study (Figure 2). The selected isolated was identified to be a Paenibacillus peoriae IBSD35. 


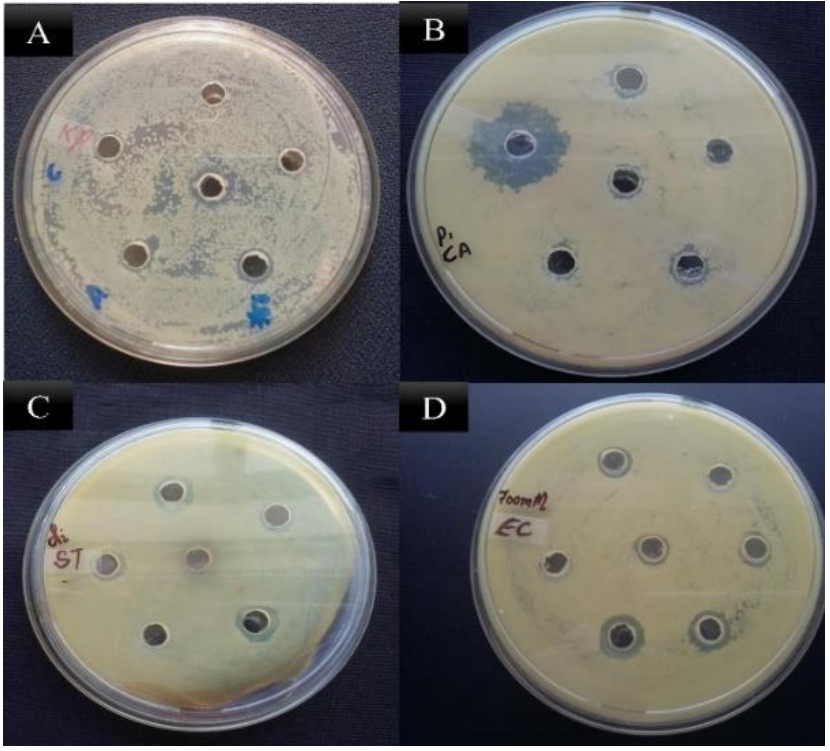

Figure 2: Antimicrobial susceptibility Test for the activity spectrum of the crude extract of IBSD35 from Millettia spp. against (A) K. pneumonia (B) C. albicans (C) $S$. typhimurium (D) E. coli (ATCC 13525).

The effect of magnesium, manganese and Tween80 on antimicrobial bioactive molecule production

Among the variables in media, proteins, $\mathrm{pH}$, phosphate, osmolality, salt concentrations, and divalent cations are known to affect the bactericidal activity of certain antimicrobial agents and microorganisms [22]. At regular intervals of incubation time, each of $4 \mathrm{ml}$ broth samples were aspirated out aseptically and their OD at $\lambda_{600}$ and $\mathrm{pH}$ were measured for the BHI, and manganese and Tween 80 supplement (Figure 2). The BHI alone broth has shown the activity on the $6^{\text {th }}$ day of fermentation. Its fermentation broth activity unit was estimated to be $1600 \mathrm{AU} / \mathrm{ml}$. The manganese supplement did not increase the biomass production $(0.079-2.231)$ and the $\mathrm{pH}$ were fluctuated between 6.29- 8.27. The antimicrobial activity was observed on the day 5 . The cells reached stationary phase after $84 \mathrm{~h}$ of fermentation. During this time, the OD of the culture increased to 2.13 and remained at that level for the remainder of the fermentation. Tween80 supplement did not increase the biomass production (0.124- 2.319). However, the antimicrobial activity was observed on day 1 but the activity loss much earlier than normal broth and decreased gradually thereafter. The production media supplemented with surplus of different ion concentration in the form of manganese $(0.008 \%)$, and a detergent Tween80 $(0.1 \%)$ and $\mathrm{BHI}$ are shown in figure 3 .

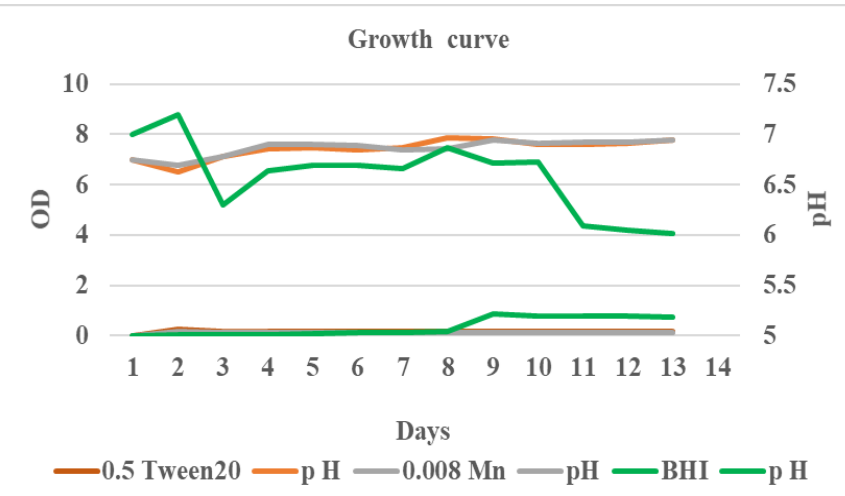

Figure 3: The growth curve of bacterial endophyte strain IBSD35 in BHI alone and supplement with Tween80 and Manganese (BHI- Green, Grey- Manganese and dark orange- Tween80).

Time-kill Analysis of the Panibacillus spp. crude extract The antimicrobials were considered bactericidal when $\mathrm{a} \geq 3$ $\log _{10}$ decrease in CFU/ml was reached compared with the initial inocula $[21,22,23]$. Therefore, we repeated the experiments with and without the use of shaker. We found no difference in colony counts when comparing these two methods. The crude extract of the endophyte IBSD35 has shown the activity at $2 \mathrm{hr}$ of incubation (Figure 4,5).

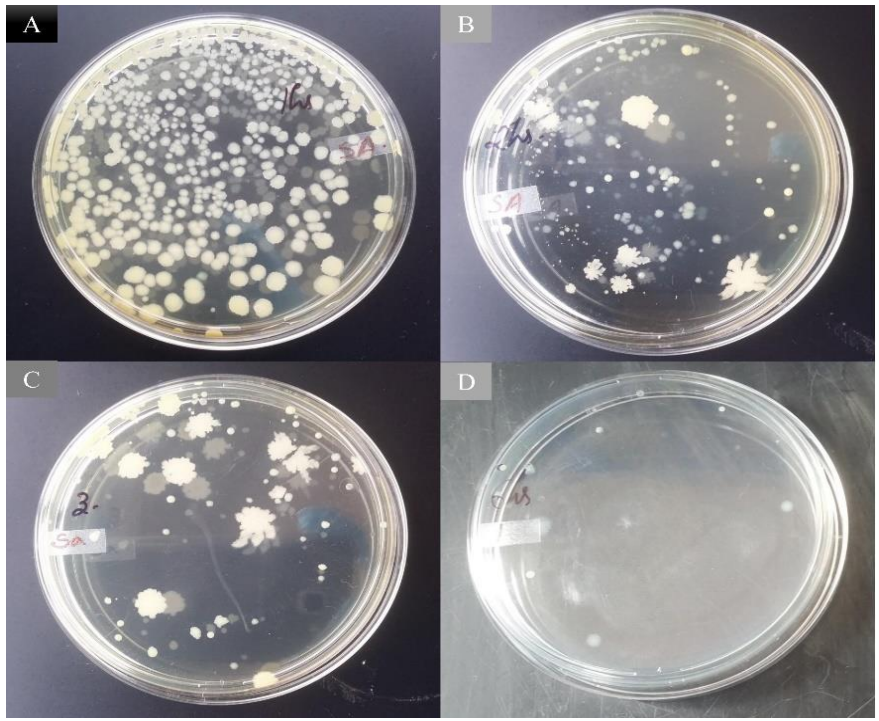

Figure 4: Time- killing bioassay at different time interval of 1, 2, 3 and $6 \mathrm{hr}$. spreading on the MHA plate seeded with of S. aureus ATCC 25923. The colony were counted using th cell counter.

The colony count of the time-killing curve from the MHA lawn was plotted and the crude extract was found equivalent to the antibiotics (Ampicillin). The left over was more in 
ampicillin. Moreover, the antibacterial action of antibiotic was faster than the crude extract (Figure 5).

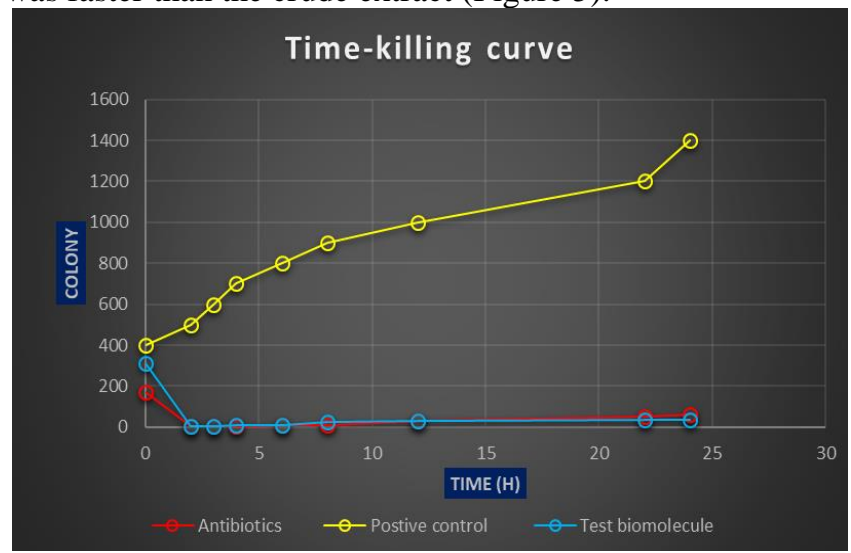

Figure 5: Time-killing curve of crude extract against $S$. aureus ATCC 25923 at different time interval for $24 \mathrm{~h}$.

(Yellow- pathogen; Red- pathogen with antibiotic; Bluepathogens with antimicrobial agent).

\section{LC-MS analysis of the dialysate of the strain IBSD35}

The LC-MS spectra of the dialysate total antimicrobial peptides were analysed and compared with the Paenibacillus database using MASCOT search algorithm [25, 26]. The antimicrobial peptide prediction with $\mathrm{CAMP}_{\mathrm{R} 3}$ tool of the endophytic bacteria protein using whole genome sequence data (fasta) has shown 1111 bactericidal stretch and a mean antimicrobial value of 0.25 . Of the several fragments of 1000 Da molecular weight, the following peptides result being part of the Paenibacillus spp. genome and alignment to find the most similar and abundant peptides in the database (Table 4) [25].

The sequences of the peptides detected in the dialysate were compared with the Paenibacillus 20180620 database using MASCOT, MS/MS ion search algorithm (data not shown) [26]. The known genomes (Panibacillus spp.) proteins or peptides searched with Mascot from the uninterpreted experimental MS/MS data base confirm the presence of antimicrobial metabolites [25]. Some of the most abundant antimicrobial peptides from the supernatant of the strain Panibacillus spp. are represented in the table 4 for further study.

Table 4: LC-MS analysis of the dialysate predicted the sequences of the peptides, their masses mass into charge ratio ( $\mathrm{m} / \mathrm{z}$ ), Post translational modification (PTM) and their similarity percentage where (+ numerical) in bracket indicated the mass of amino acids.

\begin{tabular}{|c|c|c|c|c|c|}
\hline Peptide & $\mathbf{m} / \mathbf{z}$ & Mass & PTM & AMP & $\begin{array}{c}\text { Similarity } \\
(\%)\end{array}$ \\
\hline ACATEYTAK & 479.3219 & 956.4273 & $\mathrm{~N}$ & Fusaricidine D & 40 \\
\hline MFPPVVVYK & 540.3121 & 1078.5884 & $\mathrm{~N}$ & Bacteriocin N5-2 & 35.71 \\
\hline MTTNYTSK & 473.3067 & 944.4274 & $\mathrm{~N}$ & Fusaricidin D & 37.5 \\
\hline AFTVVDHK & 458.7919 & 915.4814 & $\mathrm{~N}$ & FusaricidinD, ASP-1 & 42 \\
\hline $\mathrm{AC}(+57.02) \mathrm{TVDVHK}$ & 465.307 & 928.4437 & Y & Lipopeptide & 37.5 \\
\hline AGTLPEPLAQDGLVYR & 850.4984 & 1698.894 & $\mathrm{~N}$ & Lassomycin & 41.17 \\
\hline ATAGGVGLM (+15.99) & 886.0884 & 2655.2124 & $\mathrm{Y}$ & Macedovicin, lantibiotic & 36.66 \\
\hline SAQTAEGAMNEVCAMLTR & & & & & \\
\hline KCTLEVHK & 479.3219 & 956.5113 & $\mathrm{~N}$ & $\begin{array}{l}\text { Colistin (Polymyxin E1 and } \\
\text { E2 }\end{array}$ & 33.33 \\
\hline $\mathrm{K}(+42.01)$ ANPLSTGK & 479.3219 & 956.5291 & & $\begin{array}{l}\text { Duramycin } C \text { (Lantibiotic, } \\
\text { type } B \text {, class } 1 \text { bacteriocin }\end{array}$ & 36.84 \\
\hline $\mathrm{AC}(+57.02) \mathrm{TVDVHK}$ & 465.307 & 928.4437 & & nrps, lipopeptide & 37.5 \\
\hline $\begin{array}{c}\mathrm{M}(+15.99)(+42.01 \mathrm{z} \\
\text { CEPVLGGPNGPLAAAOAK }\end{array}$ & 941.5293 & 1880.9124 & & EP-20 (bacteriocin & 43.47 \\
\hline
\end{tabular}

\section{DISCUSSION}

During the course of this study, biologically active bacterial endophytes, Paenibacillus spp. was isolated from the traditionally used medicinal plant, Millettia pachycarpa. The bioactive secondary metabolites from the endophyte was determined from its colony and fermentation in different supplemented media. The biomolecules in the crude extract strong stability and non-toxic. The production broth supplemented with manganese ions increased the biomass production but did not necessarily increase the antimicrobial activity. Ions and detergent supplements did decrease the incubation time to produce antimicrobial biomolecules. The supplement of detergent on BHI occurred in one day. It may be suggested they may cause stress and induced the antimicrobial productions. It was observed that inoculation on simple media is easier for the purification of bioactive metabolites. The crude extract antimicrobial was best observed on the $2 \mathrm{hr}$ of incubation at $37^{\circ} \mathrm{C}$. The total antimicrobial peptides from its fermentation analyses has implications for the development of therapeutics. Discovery of novel AMPs will continue to be of great necessity as traditional screening for AMP-producing strains will increase our chance to discover new classes of AMP with 
novel killing mechanisms. Beyond the development of diagnostic techniques, the development of novel drugs is of the utmost importance to control the development of AMR.

The pathogen used evolutionary survival strategies to endure and circumvent antimicrobial killing [30]. Incidentally, there is rapid development of cross resistance with old and new antibiotics both in community and hospital-acquired infections. Alongside, they are now found in the environment too which furthermore stimulated the evolution of resistant pathogens. It is projected that there are numerous microbes which are yet to be discovered or studied and especially the unexplored North-East Region of India has huge potential to find novel microbes [10]. The rationale of selecting medicinal plants is based on its ethnobotany, endemism, biodiversity perspective and association with bioactive microbial endophytes [9, 31]. An endophyte is predominantly a bacterium or a fungus which exists in symbiotic relationship with the host plant [32, 33]. There must be a balance of the host defense and the endophyte virulence to exist together [34]. Moreover, they must secret biomolecules to adapt harsh environment [32, 35]. Numerous investigations have indicated the beneficial hostmicrobe interactions.

\section{CONCLUSION}

This discovery has demonstrated that the rainforests are a source of endophytes which produce antimicrobial biomolecules. It was observed that inoculation on simple media is easier for the purification of bioactive metabolites and produced antimicrobial metabolites at growth stage. Fusaricidin and bacteriocin are some of the most abundant antimicrobial peptides observed in its fermentation broth. The crude extract antimicrobial was best observed on the 2 $\mathrm{hr}$ of incubation at $37^{\circ} \mathrm{C}$. This reaction nature suggested that the biomolecule may be penetrating the pathogens cell membrane to cause the effect of antimicrobial. Its stable biochemical nature and reactions make our investigating biomolecules make a good candidate for the future drug development. It has a high potency comparable to the available antibiotics at the range of $1600 \mathrm{AU} / \mathrm{ml}$.

Moreover, the supplements of ions in fermentation broth may cause stress and induced the antimicrobial metabolites production in early stage. This result makes even more reasonable prospect that the intended tribal uses of this medicinal plants for the treatment of ailments may be the direct result of the antibiotics present in the tissues having been produced by endophytes. The production of antimicrobial metabolites from the fermentation has shown that the host plant may share medicinal properties with the endophytes.
The traditionally used medicinal plant and its associated biologically active microbes have huge prospect for the discovery of novel biomolecules and proved that they may have scientific, and specifically biological significance in the drug discovery. This study is a significant contribution to the knowledge of isolation of endophytes as potential sources of new biomolecule in the pharmacological industry. This study also gives clue on host-microbe interactions, and most importantly on both the endophytes and the host plant physiochemical property.

\section{ACKNOWLEDGEMENTS}

The authors would like to extend the gratitude to the laboratory members of the Microbial Resources Division, IBSD, Imphal, and Department of Biotechnology for very valuable assistance and insights. This research was funded by DBT, Government of India.

\section{FUNDING INFORMATION}

This research work is funded by Department of Biotechnology (DBT), Ministry of Science and Technology

\section{Author contributions}

NG performed all the experiment. SID and MCK supervised overall research work and drafted the manuscript. All authors read and approved the final manuscript.

\section{REFERENCES}

[1]. ECDC. Antimicrobial resistance surveillance in Europe 2014. Annual Report of the European Antimicrobial Resistance Surveillance Network (EARS-Net). European Centre for Disease Prevention and Control. 2015.

[2]. T.F. Schaberla, I.M. Hack, Overcoming the current deadlock in antibiotic research. Trends in Microbiology. Vol. 22, pp.165-167, 2014.

[3]. WHO. Antimicrobial resistance: global report on surveillance. Geneva. World Health Organization. 2014.

[4]. M. Morar, G.D. Wright, The genomic enzymology of antibiotic resistance. Annual Review Genetics. Vol. 44, pp. 25-51, 2010.

[5]. D.J. Newman, G.M. Cragg, Natural products as sources of new drugs over the last 25years. Journal of Natural Product. Vol. 70, pp.461- 477, 2007.

[6]. M. A. Fischbach, C.T. Walsh, Antibiotics for emerging pathogens. Science. Vol. 325, pp.1089-1093, 2009.

[7]. A. Stierle, G.A. Strobel, Taxol and taxane production by Taxomyces andreanae, an endophytic fungus of pacific yew. Science. Vol. 260, pp. 214- 216, 1993.

[8]. N. Myers, R.A. Mittermeier, C.G. Mittermeier, G.A.B. da Fonseca, J. Kent. Biodiversity hotspots for conservation priorities. Nature, Vol. 403, Issue. 6772, pp. 853-858, 2000.

[9]. L.L. Ling, T. Schneider, A.J. Peoples, A.L. Spoering AL, I. Engels, B.P. Conlon, A. Mueller et al., A new antibiotic kills pathogens without detectable resistance, Nature. Vol. 517, pp. 455-459, 2015.

[10]. C.H. Costello, C.L. Butler, An investigation of Piscidia erythrina (Jamaica dogwood). Journal of American Pharmacology Association, Vol. 37, Issue. 3, pp. 89-97, 1948. 
[11]. S. Goyal, D. Kumar, G. Menaria, S. Singla, Medicinal plants of the genus Sapindus (Sapindaceae)-A review of their botany, phytochemistry, biological activity and traditional uses. Journal of Drug Delivery \& Therapeutics, Vol. 4, Issue. 5, pp. 7-20, 2014.

[12]. B. Dinda, I. SilSarma, M. Dinda, P. Rudrapaul, Oroxylum indicum (L.) Kurz, an important Asian traditional medicine: from traditional uses to scientific data for its commercial exploitation. Journal of Ethnopharmacology, Vol. 23, Issue. 161, pp. 255-278, 2015.

[13]. R.C. Srivastava, Traditional knowledge of Nyishi (Dafla) tribe of Arunachal Pradesh. Indian Journal of Traditional Knowledge. Vol. 9, Issue 1, pp. 26-37, 2010.

[14]. A. K. Singhal, R. P. Sharma, J. N. Baruah, S.V. Govindan SV, W. Herz, Rotenoids from roots of Millettia pachycarpa. Phytochemistry. Vol. 21, Issue 4, pp. 949-951, 1982.

[15]. K. Clay, Fungal endophytes of grasses. Annual Reviews, Vol. 21, pp. 275-297, 1990.

[16]. O. Petrini, Endophytic fungi in British Ericaceae: A preliminary study, Transaction Britian Mycological Society, Vol. 83, pp. 510$512,1984$.

[17]. B. Schulz, C. Boyle, Review the endophyte continuum, Mycological Research, Vol. 109, Issue. 6, pp. 661-686, 2005.

[18]. B. Schulz, U. Wanke, S. Draeger, H. J. Aust, Endophytes from herbaceous plants and shrubs: effectiveness of surface sterilization methods. Mycological Research Vol.12, pp. 1447-1450, 1997.

[19]. CLSI. Performance standards for antimicrobial susceptibility testing: approved standard. 17th informational supplement. Wayne, PA: Clinical and Laboratory Standards Institute (CLSI document M100-S18). 2008.

[20] C. Ash, F.G. Priest, M.D. Collins, Molecular identification of rRNA group 3 bacilli (Ash, Farrow, Wallbanks and Collins) using a PCR probe test. Proposal for the creation of a new genus Paenibacillus. Antonie Van Leeuwenhoek, Vol. 64, pp. 253-260, 1993.

[21]. J.G. Holt, N.R. Krieg, P.HA. Sneath, J.T. Staley, S.T. Williams, Bergey's manual of determinative bacteriology (9th ed.). Lippincott Williams \& Wilkins. p. 11, 1994.

[22]. C.R. Messick, K.A. Rodvold, S.L. Pendland, Modified time-kill assay against multidrug-resistant Enterococcus faecium with novel antimicrobial combination, Journal of Antimicrobial Chemotherapy, Vol. 44, pp. 831- 834, 1994.

[23]. H.A. Nel, R. Bauer, E.J. Vandamme, L.M.T Dicks, Growth optimization of Pediococcus damnosus NCFB 1832 and the influence of $\mathrm{pH}$ and nutrients on the production of pediocin PD-1, Journal of Applied Microbiology, Vol. 91, pp.1131-1138, 2001.

[24]. C. Ruppen, and P. Sendi, Time kill assays for Streptococcus agalactiae and synergy testing, Protocol Exchange, Nature, pp.15, 2017.

[25]. B. Ma, K. Zhang, C. Hendrie, C. Liang, M. Li, A. Doherty-Kirby, G. Lajoie, PEAKS: powerful software for MS/MS peptide de novo sequencing. Rapid Communication in Mass Spectrometry, Vol. 20, pp. 2337- 2342, 2003.

[26]. G. Wang, X. Liand, Z. Wang, APD3: the antimicrobial peptide database as a tool for research and education, Nucleic Acids Research, Vol. 44, pp. D1087-D1093, 2016.

[27]. G. Brader, S. Compant, K. Vescio, B. Mitter, F. Trognitz, L-J. $\mathrm{Ma}$, A. Sessitsch, Ecology and genomic insights into plantpathogenic and plant-nonpathogenic endophytes, Annual Reviews Phytopathology, Vol. 55, pp. 61-83, 2017.

[28]. P.L. Ferguson, R.D. Smith, Proteome analysis by mass spectrometry, Annual Review on Biophysics Biomolecule and Structure, Vol. 32, pp.399-424, 2003.

[29]. D.N. Perkins, D.J. Pappin, D.M. Creasy, J.S. Cottrell, Probabilitybased protein identification by searching sequence databases using mass spectrometry data, Electrophoresis, Vol. 20, Issue. 18, pp. 551-67, 1999.

[30]. C.L.Ventola, The antibiotic resistance crisis, part 1; Causes and threats, P\&T, Vol.40, pp. 277-283, 2015.

[31]. C. Ito, M. Itoigawa, M. Kumagaya, Y. Okamoto, K. Ueda, T. Nishihara, N. Kojima, H. Furukawa, Isoflavonoids with antiestrogenic activity from Millettia pachycarpa. J. Nat. Prod. Vol. 69, Issue 1, pp. 138-141, 2006.

[32]. C.W. Bacon, J.F. White, Microbial endophytes. Marcel Dekker Inc., New York. 2000.

[33]. P. Bonfante, L.A. Anca, Plants, mycorrhizal fungi, and bacteria: A network of interactions, Annual Reviews Microbiology, Vol. 63, pp. 363-383, 2009.

[34]. M.L. Friesen, S.S. Porter, S.C. Stark, E.J. vonWettberg, J.L. Sachs, E. Martinez-Romero, Microbially mediated plant functional traits. Annual Review in Ecology Evolution and Systematics, Vol. 42, pp. 23-46, 2011.

[35]. A. Vadivalagan, R. Kannan, V. Balasubramaniam, Preliminary phytochemical analysis and antimicrobial activity of Andrographis serphyllifolia- (Rottler ex Vahl) Wight: Acanthaceae, International Journal of Scientific Research in Biological Sciences, Vol. 6, Issue. 4, pp.17-21, 2019.

\section{Supplementary Table}

Table S1: Endophytes isolated from the selected four medicinal plants.

\begin{tabular}{|l|l|l|l|}
\hline \multicolumn{5}{|l|}{ Millettia Spp. } \\
\hline Media & Endophyte & Color & Shape \\
\hline LB & IBSD17 & Reddish white & Branching \\
\hline LB & IBSD 31 & White mycelial & Branch like \\
\hline LB & IBSD 35 & Whitish & Irregular, branching \\
\hline PDA & IBSD 53 & Creamy white & Irregular \\
\hline PDA & IBSD 55 & Reddish white & Irregular \\
\hline \multicolumn{5}{|l|}{ Sapindus trifolatus } \\
\hline Media & Endophyte colony & Color & Shape \\
\hline LB & IBSD 21 & White mycelial & Branching \\
\hline LB & IBSD 22 & White mycelial dark in middle & Mycelial \\
\hline \multicolumn{5}{|l|}{ Oroxylum indicum } & Shape \\
\hline Media & Endophyte colony & Color & Irregular branching \\
\hline LB & IBSD 7 & White cottony &
\end{tabular}




\begin{tabular}{|l|l|l|l|}
\hline PDA & IBSD 5 & Yellow oily & Round \\
\hline PDA & IBSD 9 & White skimmed milk & Mycelial branching \\
\hline \multicolumn{4}{|c|}{ Unidentified vine } \\
\hline Media & Endophyte colony & Color & Shape \\
\hline LB & IBSD 1 & Dry colony & Irregular \\
\hline PDA & IBSD 2 & White gelly & Round \\
\hline PDA & IBSD 3 & White cottony & Mycelial \\
\hline
\end{tabular}

Table S2: Representative test pathogens at their optimal growth condition and media.

(NA-Nutrient Agar, TSA-Tryptic soy agar, YM-Yeast malt extract, BHI- Brain heart infusion, LB- Luria bertani).

\begin{tabular}{|c|c|c|c|c|}
\hline Sl. No. & Organisms & ATTC Code & Media & Growth condition ( $\left.{ }^{\circ} \mathrm{C}\right)$ \\
\hline 1 & Klebsiella pneumoniae & ATCC 4352 & NA & 37 \\
\hline 2 & Pseudomonas aeruginosa & ATCC 15442 & TSA & 37 \\
\hline 3 & Pseudomonas fluorescens & ATCC 13525 & NA & 26 \\
\hline 4 & Cryptococcus neoformans & ATCC 14116 & YM & 26 \\
\hline 5 & Shigella flexneri & ATCC 12022 & NA & 37 \\
\hline 6 & Candida tropicalis & ATCC 750 & YM & 25 \\
\hline 7 & Staphylococcus aureus & ATCC 25923 & TSA, LB, BHI & 37 \\
\hline 8 & Bacillus subtilis & ATCC 6633 & BHI & 30 \\
\hline 9 & Escherichia coli & ATCC 25922 & TSA, LB, BHI & 37 \\
\hline 10 & Enterococcus faecalis & ATCC 29212 & TSA & 37 \\
\hline 11 & Candida albicans & ATCC 10231 & YM & 25 \\
\hline 12 & Salmonella typhimurium & ATCC 14028 & NA & 37 \\
\hline
\end{tabular}

